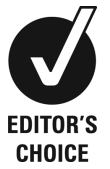

${ }^{1}$ Oral and Maxillofacial Surgery, Government Dental College, Calicut, India ${ }^{2}$ Pedodontics and Preventive Dentistry, AME's Dental College Hospital \& Research Centre, Raichur, Karnataka, India

${ }^{3}$ Plastic Surgery, Jaipur Golden Hospital, Delhi, India

Correspondence to Dr Basavaraj S Nimbeni, drbassu@gmail.com

Accepted 1 October 2014

\title{
Management of an unusual case of iatrogenic parotid sialocele using an infant feeding tube: a novel approach
}

\author{
Ambadas Kulkarni, ${ }^{1}$ Soumithran Chandrasala, ${ }^{1}$ Basavaraj S Nimbeni, ${ }^{2}$ \\ Surendar Pal Singh, ${ }^{3}$ Shruti Golai ${ }^{2}$
}

\section{SUMMARY}

Injuries to the parotid duct and parenchyma resulting in swelling in the cheek region commonly present in maxillofacial practice. Sialocele is a discrete collection of saliva in a subcutaneous cavity that can be iatrogenic, idiopathic or the result of post-traumatic injuries to the duct or parenchyma, presenting as a salivary pseudocyst or retention cyst. We present an unusual case of parotid sialocele following surgery for sialolithiasis which presented with progressive painless swelling in the preauricular region of 9 months duration. Treatment included surgical exploration under local anaesthesia and draining the cavity by keeping the opening patent using an infant feeding tube.

\section{BACKGROUND}

Sialocele or salivary pseudocyst is an uncommon complication following trauma or surgery involving the parotid gland. ${ }^{1}{ }^{2}$ A sialocele is an extraglandular collection of saliva in a subcutaneous cavity following disruption of the parotid duct or parenchyma. ${ }^{3}{ }^{4}$ Clinically, sialocele appears as an asymptomatic soft mobile swelling, occasionally fluctuant, which, if left untreated, may rupture and develop into a salivary fistula. ${ }^{5}$ Diagnosis can be made by fine needle aspiration cytology, sialography, contrast CT and MRI. The various treatment options recommended include repeated aspirations and compression dressings, antisialogogues, parasympathetic denervation (tympanic neurectomy), percutaneous sclerotherapy, sialography, sialendoscopy, botulinum toxin $^{7}$ and injection of hypertonic saline into the gland. ${ }^{8}$

\section{CASE PRESENTATION}

We report a case of iatrogenic parotid sialocele in a 47-year-old man who presented to our maxillofacial unit with a chief complaint of painless swelling over the right side of the face of 9 months duration (figure 1). The patient was apparently normal 1 year previously but started experiencing a dull pain in the right preauricular region which worsened after having food. Past dental history revealed that he was diagnosed with right parotid sialolithiasis 10 months earlier, for which he underwent surgery.

The sialolith was located inside the parotid duct but the dimensions were not known as the patient had undergone surgery at another specialty centre for oral and maxillofacial surgery. The sialolith was

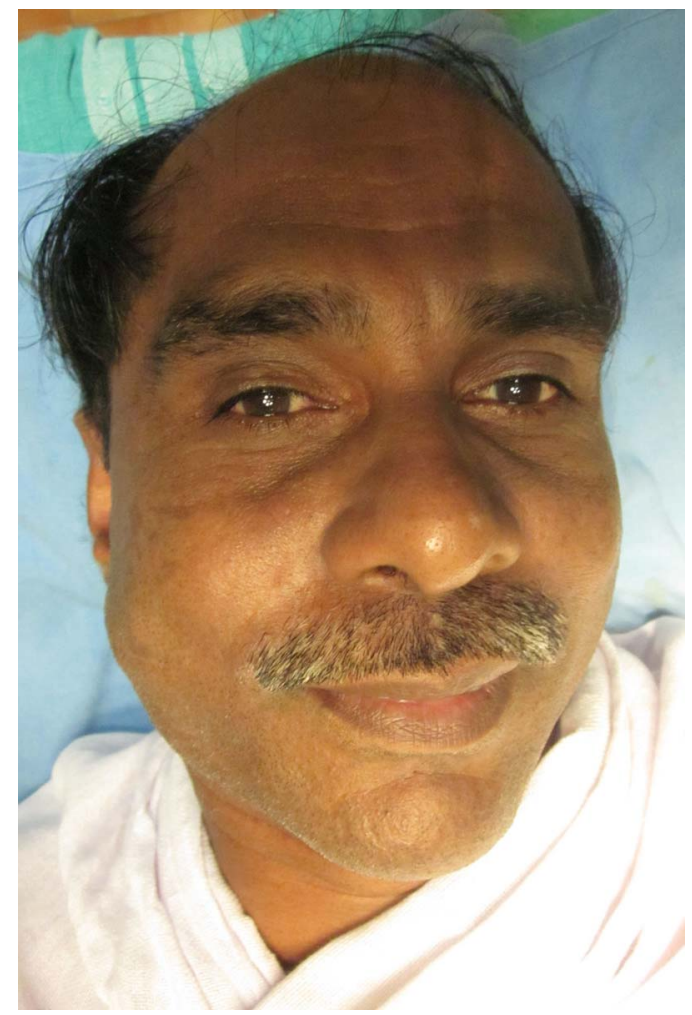

Figure 1 Extraoral swelling in the preauricular region on the right side.

removed from the duct by an extraoral approach by making a skin incision parallel to the parotid duct and blunt dissection was performed to expose the duct. The sialolith was removed in piecemeal fashion.

One month after surgery the patient observed swelling in the cheek region which was asymptomatic. It gradually increased in size, with occasional reduction followed by a further increase. The medical and family history was non-contributory. On examination there was a $3 \times 4 \mathrm{~cm}$ diffuse non-tender swelling in the right preauricular region which was fluctuant. The skin over the swelling did not show any discolouration, erythema or purulent discharge but there was a scar which showed the incision placed during the previous surgery (figure 2); no associated lymphadenopathy was detected. Intraorally, the mucosa was normal without evidence of any infection (figure 3). A diagnosis of sialocele was made by ultrasonography and analysis of aspirate for salivary amylase. 


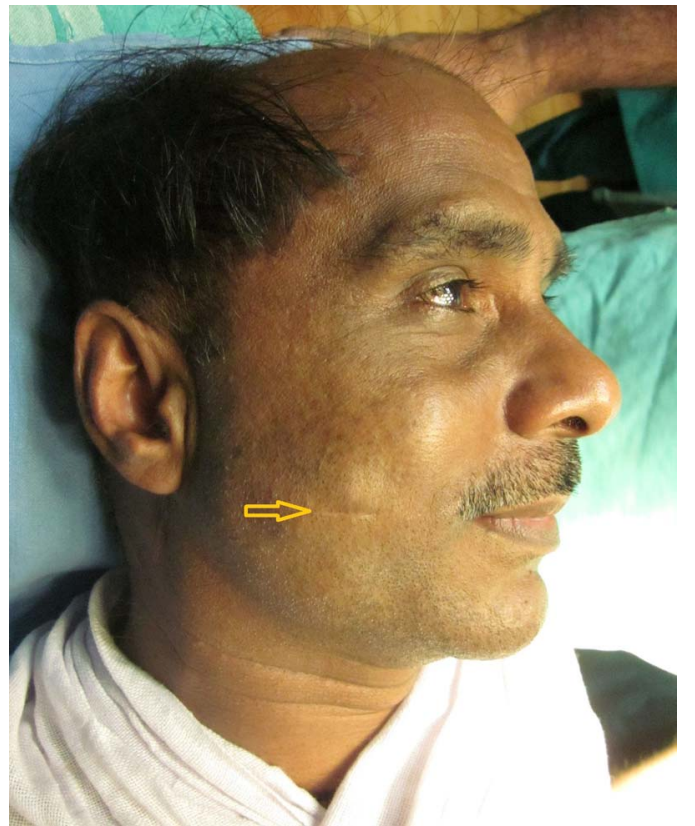

Figure 2 Scar showing the incision placed during previous surgery.

\section{INVESTIGATIONS}

- Fine needle aspiration cytology

- Ultrasonography

- Sialography

- Analysis of aspirate for salivary amylase

\section{TREATMENT}

As a primary modality of treatment, aspiration and compression dressings were used but the swelling reappeared after 2 weeks so

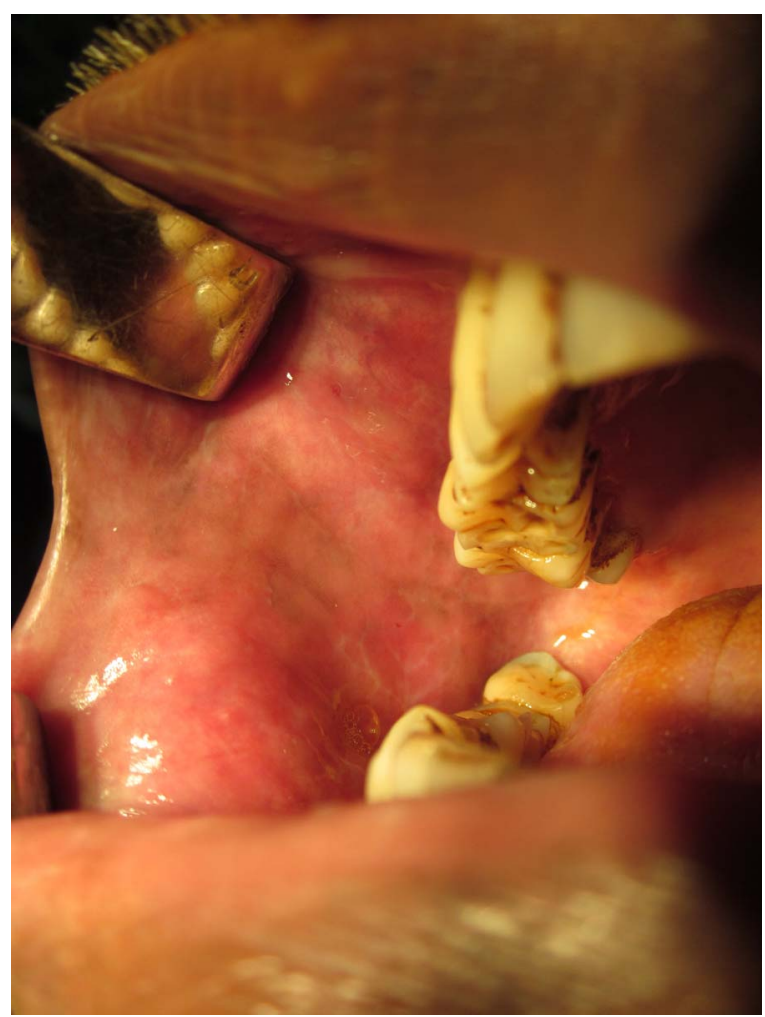

Figure 3 Intraoral view showing normal mucosa.

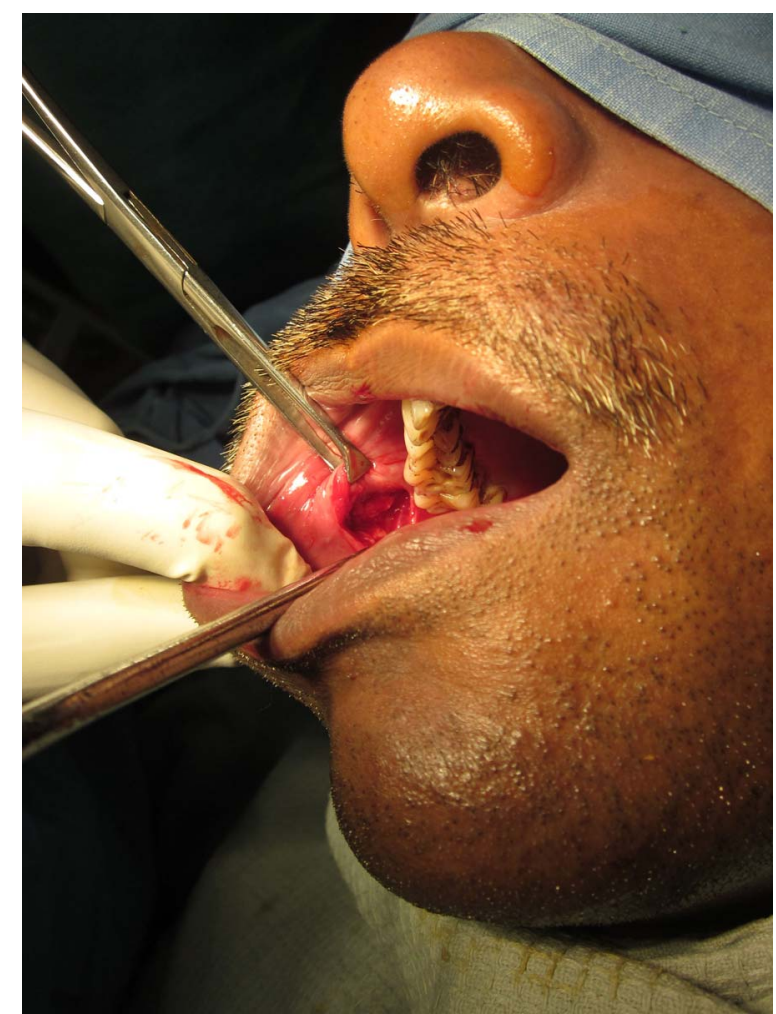

Figure 4 Intraoperative view showing the incision and surgical exploration of the parotid duct.

surgical decompression was planned. After baseline investigations the patient underwent intraoral surgical exploration under local anaesthetic using lignocaine $2 \%$ with adrenaline 1:100 000. A horizontal incision was placed $1 \mathrm{~cm}$ below the ductal orifice and the site was carefully explored to reach the cavity (figure 4). Once the lining was incised, straw-coloured serous fluid was visible. The cavity was irrigated with saline and an infant feeding tube no. 6 was taken and both ends were cut to achieve a length of $4 \mathrm{~cm}$. The tube was kept in the cavity and secured to the cavity ends by suturing it with $4 / 0$ Vicryl sutures. The mucosal incision was closed after proper haemostasis, by keeping approximately $1 \mathrm{~cm}$ of the tube outside (figure 5). This created an intraoral fistula as one end of the tube remained within the sialocele while the other end drained saliva into the oral cavity. Follow-up revealed no signs of sialocele formation with scanty flow of saliva from the tube and the patient was discharged on the third postoperative day (figure 6).

\section{OUTCOME AND FOLLOW-UP}

The wound healed uneventfully without any complication and the tube was removed after 10 days once it had stopped draining saliva. The patient was followed up at weekly intervals for the first 2 months and then once a month for the next 6 months. No signs of recurrence were noted during the follow-up observation period.

\section{DISCUSSION}

Iatrogenic parotid sialocele is an uncommon complication usually seen after surgery in and around the parotid gland. The causes of iatrogenic parotid sialocele include injury to the main duct, accessory duct, parenchyma of the gland and stricture of the duct. A thorough knowledge of the anatomy of the parotid gland and its relationship with other structures in the cheek are 


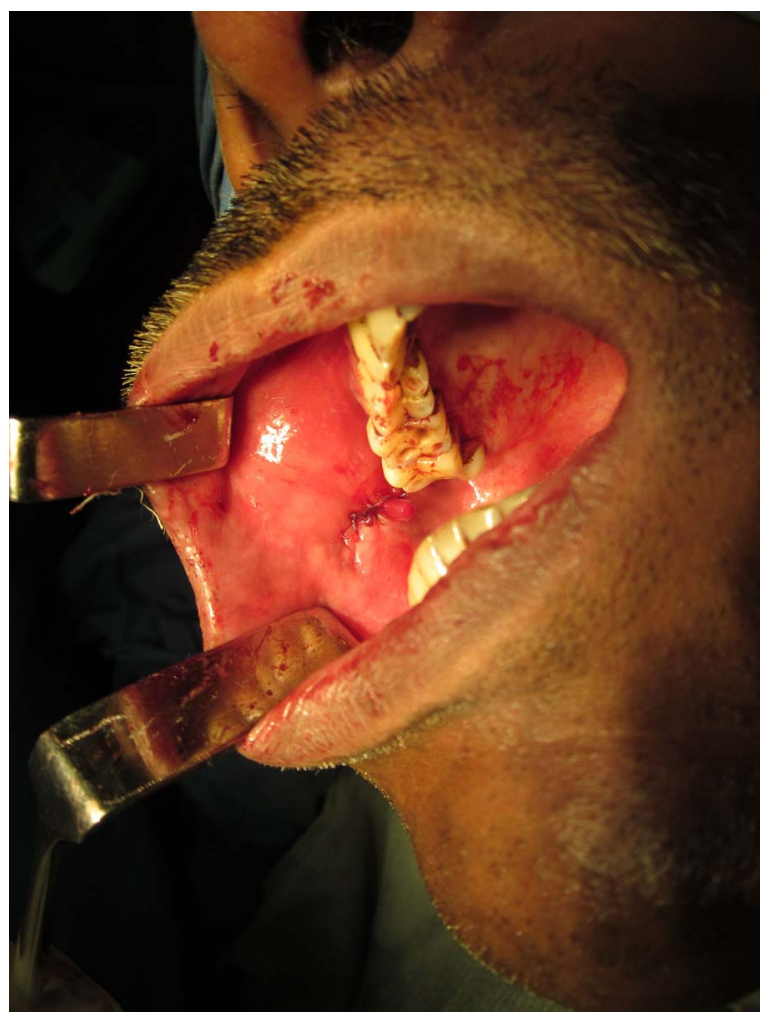

Figure 5 Immediate postoperative view showing the infant feeding tube in place.

essential when treating the pathology. The diagnosis of this condition has become easier as a result of recent investigative methods such as biochemistry of the aspirate for salivary amylase, Doppler ultrasonography, contrast CT and MRI. Most sialoceles are managed conservatively by percutaneous needle aspiration. ${ }^{9}$ However, resistant cases are managed either by diverting the parotid secretions into the mouth by reconstruction of the duct or creation of a controlled internal fistula or by depressing the parotid secretions by duct ligation, injection of sclerosants, hypertonic saline and botulinum toxin. ${ }^{10}$ We believe this is the first case of iatrogenic parotid sialocele to be managed

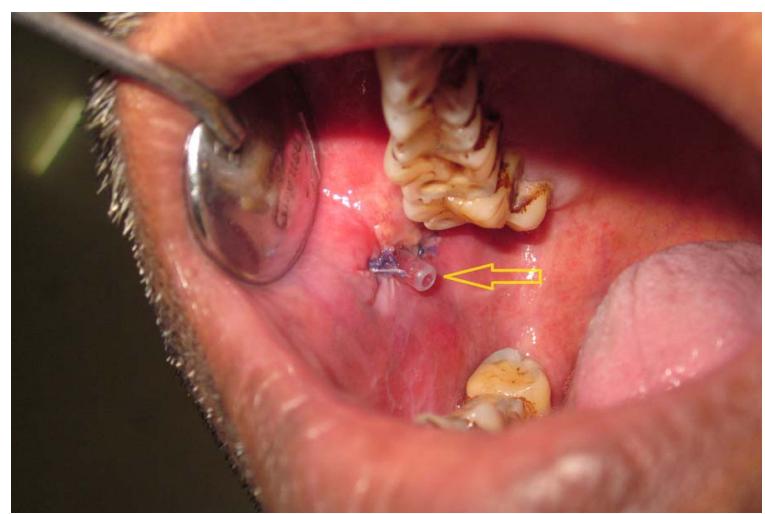

Figure 6 Postoperative view showing wound healing with $1 \mathrm{~cm}$ of the tube outside the mucosa. by using an infant feeding tube. The purpose of placing an indwelling tube in the cavity is to drain the sialocele completely, and it is thought that the sialocele resolves spontaneously after 4 weeks due to formation of granulation tissue around the margins of the salivary parenchyma to seal any further extravasation of saliva. The infant feeding tube used in this technique did not cause any untoward hypersensitivity reactions. However, long-term randomised studies are needed to prove the efficacy of this technique compared with other methods for the management of sialocele.

\section{Learning points}

A sialocele is an extraglandular collection of saliva in a subcutaneous cavity following disruption of the parotid duct or parenchyma.

- A sialocele can be iatrogenic, idiopathic or caused by post-traumatic injuries to the duct or parenchyma.

- Clinically, a sialocele appears as an asymptomatic soft mobile swelling, occasionally fluctuant, which, if left untreated, may rupture and develop into a salivary fistula.

- Diagnosis can be made by fine needle aspiration cytology, sialography, contrast CT and MRI.

- Among various treatment modalities, the present case of iatrogenic sialocele was managed by a novel approach using an infant feeding tube.

Acknowledgements The authors thank Dr Shruti Nimbeni, Assistant Professor, Department of Pediatric Dentistry at AME Dental College \& Hospital, Raichur.

Contributors AK performed the surgical procedure; SPS followed up the case during recall visits; SC monitored the overall progress of the patient; BSN prepared the manuscript.

Competing interests None.

Patient consent Obtained.

Provenance and peer review Not commissioned; externally peer reviewed.

\section{REFERENCES}

1 Medeiros JúniorR, Rocha NetoAM, et al. Giant sialocele following facial trauma. Braz Dent J 2012;23:82-6.

2 Bater MC. An unusual case of preauricular swelling: a giant parotid sialocele. Int J Oral Maxillofac Surg 1998;27:125-6.

3 Witt RL. The incidence and management of siaolocele after parotidectomy. Otolaryngol Head Neck Surg 2009;140:871-4.

4 Chen WL, Zhang LP, Huang ZQ, et al. Percutaneous sclerotherapy of sialoceles after parotidectomy with fibrin glue, OK-432, and bleomycin. Br J Oral Maxillofac Surg 2013;51:786-8

5 Canosa A, Cohen MA. Post-traumatic parotid sialocele: report of two cases. J Oral Maxillofac Surg 1999;57:742-5.

6 Steinberg MJ, Herréra AF. Management of parotid duct injuries. Oral Surg Oral Med Oral Pathol Oral Radiol Endod 2005;99:136-41.

7 Chow TL, Kwok SP. Use of botulinum toxin type $A$ in a case of persistent parotid sialocele. Hong Kong Med J 2003;9:293-4.

8 Chhabra N, Chhabra S, Kapila SA. Use of hypertonic saline in the management of parotid fistulae and sialocele: a report of 2 cases. J Maxillofac Oral Surg 2009;8:64-7.

9 Araujo MR, Centurion BS, Albuquerque DF, et al. Management of a parotid sialocele in a young patient: case report and literature review. J App/ Oral Sci 2010;18:432-6.

10 Parekh D, Glezerson G, Stewart M, et al. Post-traumatic parotid fistulae and sialoceles. A prospective study of conservative management in 51 cases. Ann Surg 1989:209:105-11. 
Copyright 2014 BMJ Publishing Group. All rights reserved. For permission to reuse any of this content visit http://group.bmj.com/group/rights-licensing/permissions.

BMJ Case Report Fellows may re-use this article for personal use and teaching without any further permission.

Become a Fellow of BMJ Case Reports today and you can:

- Submit as many cases as you like

- Enjoy fast sympathetic peer review and rapid publication of accepted articles

- Access all the published articles

- Re-use any of the published material for personal use and teaching without further permission

For information on Institutional Fellowships contact consortiasales@bmjgroup.com

Visit casereports.bmj.com for more articles like this and to become a Fellow 